Check for updates

Montreal, Canada

Cite this as: BMJ 2021;373:n1359

http://dx.doi.org/10.1136/bmj.n1359

Published: 26 May 2021

\section{Covid-19: Variants are spreading in countries with low vaccination rates}

\author{
Owen Dyer
}

With new daily covid-19 cases in steep decline across Europe and North America, and now falling in India, the curve of global daily mortality is trending downwards. But the virus continues to flare up, most recently in Cambodia, Malaysia, Singapore, Taiwan, Thailand, and Vietnam-countries often cited as models of pandemic control.

Taiwan's covid-19 death toll has more than doubled in one week-to 23 deaths in all. Having recorded just 135 locally acquired infections in the entire pandemic up to 14 May, Taiwan has since detected over 4000 cases as the country's atrophied testing system struggles to keep up with new suspected cases. Covid testing had largely been abandoned even in cases of fever, such was the disease's rarity in Taiwan.

Case numbers have also surged in parts of South America, where mortality has been on a different scale of magnitude. Argentina has the world's highest per capita death rate, having seen 493 deaths a day on average over the past week, or 10.8 deaths per million people per day, compared with 9.4 in Colombia, 8.8 in Brazil, and 1.6 in the US. Argentina's toll this week was proportionally higher than the worst week seen in Colombia, Peru, or the US, though less deadly than the worst weeks in Brazil, Hungary, or the UK.

Argentina began a strict lockdown on 21 May, set to run for nine days. "We are living the worst moment since the pandemic began,” President Alberto Fernández said in a televised message announcing the measures. "It is vital that the authority of each jurisdiction apply the rules that we are dictating. There is no room for speculation or doubt.” The government's social distancing measures have met fierce political resistance, not least from the man expected to challenge Fernández in the next election, Buenos Aires mayor Horacio Rodríguez Larreta.

Larreta recently took the government to the Supreme Court for the right to keep in-person schooling open in the capital city, and won. He has now agreed to close schools temporarily as the new wave has brought a rare moment of political unity. Other opposition supporters, however, promised a mass protest against the lockdown on 25 May.

With $75 \%$ of the country's intensive care places already full and hospital admission increasing, "we face a risk of saturation of the health system," warned Fernández. The case fatality rate is growing, a sign of overstretching.

Argentina's doctors are exhausted after 10 months in which the seven day average of daily cases did not fall below 5000. Across South America where the P.1 "Brazilian" variant circulates, the troughs between the waves are never very low. Brazil's own curve deaths in Chile and Colombia have also plateaued at relatively high levels. South America has the highest covid death rate of any continent, 1785 deaths per million, and it is on course to increase in the coming months.

In Taiwan, the B.1.1.7 "UK" variant is surging. It was brought in by airline flight crew, who faced lighter restrictions than other travellers. Some of these visited Taipei's teahouse, or adult entertainment, district, creating a mass transmission event. Taiwan's contact tracers have struggled to follow the outbreak, as people are reluctant to admit being in the area.

In Singapore, a recent spike in cases was blamed on the B.1.617 "Indian" variant, which has also driven recent surges in Nepal and Thailand. Experts in Singapore and Taiwan said that health systems had become complacent, placing their faith in border controls which worked well, until they failed.

\section{Lack of vaccines}

The common denominator in these countries is shortage of vaccines. Japan, another country that has lagged in vaccinations, has also seen a recent spike in infections, concentrated on Osaka, where hospitals are overwhelmed. Mass vaccination centres opened across Japan on 24 May. Most offer the Moderna vaccine which was only approved in Japan on 21 May. The AstraZeneca vaccine was approved at the same time but is not yet being distributed.

Japan required extra, locally based trials of the vaccines before approval, a delay the government said was necessary to allay widespread vaccine hesitancy. Having vaccinated only about $2 \%$ of its population with the Pfizer vaccine, Japan is now beginning mass immunisation just two months before it plans to host the Olympic Games, for which public support plummeted to $14 \%$ in the most recent poll.

In Taiwan, fears about the country's main stockpiled vaccine AstraZeneca gained wide currency, and only about $1 \%$ of Taiwan's 23 million people have received a shot. Demand has shot up since cases spiked, but there are only 300 ooo doses available.

Argentina initially leaped ahead of its neighbours in vaccinations but was then hit by supply chain failures. Newspapers now report each landing of aircraft from China and Russia bringing Sinopharm and Sputnik vaccines, which account for most of the 12 million vaccine doses the country has received so far. The government has promised 4 million more doses in the next few days. Some $19 \%$ of the population have received at least one vaccine, and $5.3 \%$ are fully vaccinated. Ultimately, Argentina increasingly resembles a steady flood. Cases and 
expects to manufacture its own vaccine under an agreement with AstraZeneca. 